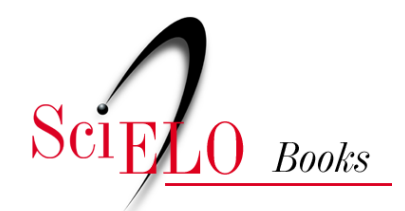

\title{
Conferência de abertura \\ Direitos Humanos e a Saúde Mental: estratégias para o avanço das políticas de saúde mental
}

\author{
Benedetto Saraceno
}

\section{SciELO Books / SciELO Livros / SciELO Libros}

SARACENO, B. Direitos Humanos e a Saúde Mental: estratégias para o avanço das políticas de saúde mental. In: BARROS, S., BATISTA, L.E., and SANTOS, J.C., comps. Saúde mental e reabilitação psicossocial: avanços e desafios nos 15 anos da Lei 10.2016 [online]. Uberlândia: Navegando Publicações, 2019, pp. 11-23. ISBN: 978-65-81417-07-9.

https://doi.org/10.7476/9786581417079.0002. Transcrição dos Anais do II Encontro de Saúde Mental - Reabilitação Psicossocial: avanços e desafios 15 anos após a Lei 10.216, Uberlândia, MG, 2016.

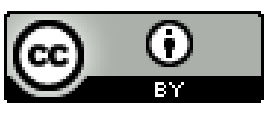

All the contents of this work, except where otherwise noted, is licensed under a Creative Commons Attribution 4.0 International license.

Todo o conteúdo deste trabalho, exceto quando houver ressalva, é publicado sob a licença Creative Commons Atribição 4.0.

Todo el contenido de esta obra, excepto donde se indique lo contrario, está bajo licencia de la licencia Creative Commons Reconocimento 4.0. 


\section{Conferência de abertura - Direitos Humanos e a Saúde Mental: estratégias para o avanço das políticas de saúde mental}

\section{Prof. Dr. Benedetto Saraceno}

Médico, Psiquiatra, Ex-diretor do Departamento de Saúde Mental da Organização Mundial da Saúde, Docente da Universidade de Genebra, Suíça e Coordenador do Curso de Mestrado Internacional de Políticas e Serviços em Saúde Mental da Universidade Nova de Lisboa.

Desculpe, eu voy hablar en español. Com algumas palavras, as poucas que conoszco en português. Entonces vá a ser un portunhol. Eu acho que vamos ter essa dificuldade... entender a minha fala. Antes de todo, eu queria agradecer a Escola de Enfermagem da USP e a professora Sônia Barros por invitarme. Este evento - que é um evento importante - porque está em um contexto muy complicado, muy difícil do país, da saúde no país e da saúde mental. Nós es solamente um problema de agradecer, de maneira assim, formal, de cortesia. Sino de homenagear a professora Sônia Barros que durante toda a sua vida assim como uma acadêmica, uma pesquisadora, una maestra de muitos e de muitas que estão aqui. E ha sido, sobretodo una militante. Entonces agradecer pela sua contribuição militante, vigorosa ao processo de construção da reforma psiquiátrica no Brasil. Professora Sônia,obrigado.

\section{Ahora voy...}

Mi conferência se chama Connectivity, o sea, conexão. Fundamentalmente eu voy a falar de três tipos de connectivities. A conexão que existe entre os determinantes sociais e discapacidad. A segunda connectivity é a connectivity entre direitos humanos e desinstitucionalização. E a terceira connectivity é a connectivity entre a reabilitação e a reorientación ou reorientação do sistema saúde mental. Vamos pensar a primeira connectivity o sea, a connectivity entre determinantes sociais e discapacidad. A dimensão social pelas enfermedades mentales é uno componente fundamental da história natural das enfermedades e da enfermedad mental. La enfermedad e los determinantes sociales están en una relação circular. Se vocês quieren empezar a mirar esta circulari- 
dade pode ser que vá empezar por aqui. Vá empezar con una condición de problema de saúde mental. Vá empezar hacia la direita. O problema de saúde mental determina una iniquidade social. Por quê? Porque o paciente - tomamos um paciente com esquizofrenia - um paciente com esquizofrenia empeza a sua carreira de paciente baixando escalera de sua capacidad social. Perde o trabalho. A família se vá. Está islado. Consume o dinheiro da família.

Então assim: entra dentro de um círculo de pérdida de capacitação social. E eso determina um aumento da vulnerabilidade, que é uma vulnerabilidade de vida. A enfermidade se une à uma uma vulnerabilidade de vida, a pérdida de contractualidad social. Se o paciente entra na psiquiatria tradicional, no manicômio aún más. Entonces hay uma circularidad em que podemos empezar la Etapa 01, que é a enfermedad hacia pérdida da contractualidad social. Ou podemos empezar do outro lado: uma pessoa tem una pérdida da contractualidad social, porque está pobre, tem deuda. Porque está... Sufre de exclusão social e empeza a tener una vulnerabilidade social. E de la vulnerabilidade social marcha hacia um problema de saúde mental, hacia una enfermedad mental. Entón, que quer decir? Que hay lo que se llama risk reciprocity. O sea, una reciprocidade do riesgo. Tá. Mas que quiere decir?

Que as desigualdades sociales son fatores de riesgo para a saúde mental e que las enfermedades mentales son fatores de riesgos para desigualidades sociales. Esta relação... Não es que todas las enfermedades tengan la misma... mecanismo. É claro que enfermedades como depressão, uso de álcool e droga, transtorno de desarrollo de niño, adolescente são enfermedades que estão fortemente determinadas, por determinantes sociales: pobreza, exclusão social, falta de... Nível educacional muito baixo. Al revés, hay outras que son enfermedades que tem uma componente biológica importante, como a esquizofrenia. Pero no importa. Porque ellas entran também, de outro lado, na determinação da descença de la escalera social do paciente, o usuário. Hay una... Esta doble via, que se llama social causation, o sea, es una causa social la que vá determinar la enfermedad, o el social drift; es una enfermedad que vá determinar una pérdida de capacidade social. Hay un clássico que foi publicado en la revista Nature hace 20 años, que es um artículo fundamental. E foi escrito por um amigo de Brasil, um amigo da Reforma, o padre da Conferência de Caracas, o professor Isaac Levav, que escribió este artículo, que es un clássico da epidemiologia, em que mostra que há enfermedades que son determinantes de pérdida de valor social: depressão, alcoolismo e outras que vão en el otra direção. Porém, la pobreza, la deuda, la vulnerabilidad social, la depression, el suicidio son determinados por determinantes sociales. 
La esquizofrenia es un determinante de vulnerabilidade social de unemployed, de desempleo e finalmente, de pobreza. É un estudio muy interessante, que mostra que la capacidad econômica de um usuário que tem esquizofrenia quando tem 20 años, aos 30 anõs depois sua capacidade econômica ha diminuido $70 \%$. O sea, se ele tenía uma família, se ele tenía... O sea, se ha venido empobrecendo, o seu valor social. Ha venido empobrecendo sempre. Estamos hablando de uma connectivity entre determinantes sociales e discapacidad. O sea, los determinantes sociales son, determinam discapacidades. Eso es importante, una cosa teórica. Porque es una gran... Es una gran información para quién queira hacer reabilitação. Porque se hay una connectivity entre deteminante social e discapacidad, se nosotros queremos abordar discapacidad, nosotros que nos llamamos reabilitadores de la discapacidad. No podemos dirigirnos solamente hacia la discapacidad individual, do usuário. E sim dirigir-nos também hacia la desvantagem social em que o usuário se encontra. Eso é fundamental. No hay reabilitação piscossocial se hay solamente trabalho sobre a discapacidad individual do usuário. Eso es mala reabilitação. A boa reabilitação é una reabilitação que trabalha sobre a discapacidad individual e que trabalha também sobre a desvantagem social em que se encontra o usuário. Entonces el trabalho de reabilitação psicossocial é um trabalho doble: individual e de contexto. Toda a reabilitação da psiquiatria psicossocial está dirigida à discapacid individual do paciente.

Eu sempre dou o mismo exemplo, tomado da discapacidad física. Se um senhor tem uma discapacidad física porque no pude levantar a perna, no tiene la capacidad de hacer esto. Hay dos tipo de reabilitação. Hay una reabilitação que aprende o paciente a levantar mais a perna. E hay outra reabilitação que contemporaneamente aprende o paciente a levantar a perna e aprende também a cidade, o prefeito a baixar la grade do bus. Essa é a reabilitação. A reabilitação é um doble trabalho. Um trabalho para que o paciente aprenda a habilidades e o contexto social diminui a resistência hacia a discapacidad individual do paciente. Esta é a boa reabilitação. A reabilitação psiquiátrica de muñequitas, cenizeros, pintar... no disminuye la desvantagem social. Quizás no aumenta tampoco las habilidades do paciente. Esta conectividade que existe entre deteminantes sociais e a discapacidad. Porque a discapacidad tem dentro, en si misma, una componente social fundamental. A segunda conectividade é a conectividade entre os derechos humanos e a desinstitucionalização.

Bom, violaciones de derechos humanos. Quem sou eu para venir a Brasil falar de defensa de derechos humanos, saúde mental, o movimento, a história do Brasil, a luta aqui, manicomial é una história centrada sobre a lucha por los derechos humanos do paciente. Todos los países, alto y bajo ingreso son violadores de derechos humanos. Que 
hay un cuento, que hay un mito que las violaciones de direitos humanos na psiquiatria ocurren siempres nos países remotos, da África, siempre nos países exóticos. Não. Violação dos direitos humanos é uma violação sistemática que ocurre na Suécia, na Francia, na Alemanha, na Suíça. Na minha ciudad, donde eu vivo, Ginebra, é uma cidade... É um manicômio de 300 camas, com a gente amarrada à cama, com a cela de isolamento. $\mathrm{Na}$ Suíça. Têm bancos e violaciones de direitos humanos. Ambos. Nos países remotos, dos pobres, não tem banco e têm violaciones de derechos humanos. Está a diferencia entre a Suíça e o Cameroon.

Todos los ambientes terapêuticos pode ser lugar de violaciones de direitos humanos. Não é solamente um problema de hospital psiquiátrico. A violación de direitos humanos ocorria no hospital piquiátrico, no servicio da comunidade, na Casa de Medio Camino, num apartamento protegido. Na cárcel. Na casa mesmo do paciente. Esta não é una violação do derecho humano que está ocorrendo dentro da psiquiatria. Está dentro da comunidade. É a mesma comunidade que está violando direitos com o paciente, com o usuário. Eso es un niño, existem niños que estan encadenados. Não están en un hospital pisquiátrico, están no pueblo. Nesta comunidade que está violando direitos humanos. Eso es interessante. Eso es un templo religioso hindu que hace cuidado de salud mental com una cosa espiritual. Cosa espiritual por estar en una cadeira a pessoa. Eso es un hospital psiquiátrico. Eso es un hospital psiquiátrico da União Europeia. Interessante hã? Eso es un hospital psiquiátrico de um país membro da União Européia, que ha tomado a presidência da União Européia durante seis meses. Esse país, esse hospital psquiátrico forense, judiciário, da Lituânia, da cidade de Vilnius.

Entonces, em toda parte do mundo hay violação de direitos humanos. No se confundem: a pobreza da estrutura, da infraestrutura, da logística como sinal da violação de direitos humanos. Hay hospitales psiquiátricos muy pobres na África, por exemplo, donde hay menos violaciones de derechos humanos. E hospitales psiquiátricos muy limpios nos países do norte da Europa en que uno no vê a pobreza no contexto da logística, pero la violação dos direitos humanos, está. Entonces hay que tener um ojo inteligente para evaluar a presencia, maior ou menor do viés. O instrumento Quality Rights da Organização Mundial de Saúde, OMS, é exatamente isso. Ajuda a tener una mirada inteligente dentro do contexto de um local de saúde mental para ver se a violação de derechos humanos está ocurriendo, apesar do baño limpo, que é todo limpo, todo una maravilha. E violacíon hay. $\mathrm{E}$ a veces vai visitar hospitais psiquiátricos muito pequenos, pobres, de países africanos e um clima bastante humano. Apesar que o contexto, a logística é terrível. 
La Convención da ONU sobre os direitos das pessoas com discapacidad - no discapacidad mental - discapacidad en general é muito importante ter sido firmada e ratificada por Brasil. Então o tempo constitucional. Então se o Brasil viola a Convenção de Direitos, já firmado, pode ser posto em juicio internacional para a Corte. Eu penso que no próximo futuro eso es un instrumento que tenemos que utilizar mais. O sea, abogados que ponen en Corte Internacional o gobierno por violar a Convenção.

Que está firmado o governo nisso. E primeira característica desta Convenção que foi aprovada em 2008 e firmada em 2009 é que o físico e o mental estão juntos. A Convenção fala de discapacidad. Não de discapacidad mental, discapacidad... Discapacidad. E eso es importante. Porque é um avanço para a discapacidad mental estar dentro, na discapacidad em geral.

Segundo: la discapacidad em si no puede ser ningun motivo de limitação da libertad. Eso es un princípio que está transversal em toda a Convenção. Eu aviso que no programa alguém vai falar com mais profundidade, profundamente, da Convenção, desto. E a coisa interessante da Convenção é que passa da etiqueta à ética. A etiqueta é uma ética chiquita, pequeña. Aos psiquiatras le gusta a etiqueta, a ética pequena. E que é a etiqueta dos psiquiatras? É falar sempre do... Ah, os direitos humanos. Todos falam. Em congresso mundial de psiquiatria, sempre estavam falando de direitos humanos. $\mathrm{O}$ mismo que es un violador dos direitos. $\mathrm{O}$ mesmo que no seu local psiquiátrico viola os direitos humanos. Então, a Convenção está basada sobre o grande slogan do movimentos dos usuários europeus: nada sobre mim, sem mim. Nothing about me, without me. Que acho fundamental. Não podemos falar do usuário sem o usuário. Se o usuário não está, não podemos falar.

Agora, a Convenção tem vários artigos. É uma Convenção grande. Eu chamo sua atenção sobre um artículo, o artículo 14, que é um artículo muito discutido, controversial. Pero lo interessante, lean lo que está em rojo. Que dice? Dice que el ejercicio de la capacidad jurídica respete los derechos, la voluntad y la preferencia de la persona. $\mathrm{O}$ sea, no hay ninguna razón por, al ser discapacitado, la voluntad, la capacidad jurídica da pessoa com discapacidad sea disminuida. No capítulo... No artículo 15 se habla de... La Convenção defende as persona para que no sean sometidas a torturas, tratos o ofensas crueles, inumanos o degradantes. Muita gente diz: mas o que é eso? Parecen que los hospitales psiquiátricos hacen tortura. En el language da ONU, en el language jurídico da ONU um maltrato a um paciente é uma tortura. Está dentro da categoria tortura e trato inumano. Entonces a psiquiatria está aqui. Está. O artículo 19, fundamentalmente, que diz? Diz que a gente tem que estar donde quer. Que se quiere estar na comunidad tem 
direito. E tem direito de estar na comunidad com o apoio. O apoio: a moradia, a vivenda, a alimentação, o trabalho, inclusão social. O programa do Braços Abertos.

O que é o programa do Braços Abertos? O programa do Braços Abertos é permitir à gente de viver na comunidade e não estar dentro do local de psiquiatria ou no cárcere. E com una prestação social. Esto no é um movimento da luta manicomial do Brasil. A psiquiatria diz que é de Trieste. Esta Convenção é de Naciones Unidas. E se o governo de Brasil viola esto, não viola la Lei de Trieste. No está violando la Lei de Tykanori, la Lei de Pedro Gabriel Delgado, ou de Domingos Sávio do Nascimento. Está violando uma Convenção firmada pelo governo do Brasil. Porque la história da saúde mental e de la discapacidad mental severa é uma história de negação. No Brasil, o hospital psiquiátrico é uma cidade inventada; é uma cidade artificial, islada da comunidade. Pero la desospitalização selvage - que passou em vários países - fué na outra forma, de una otra respuesta de delegación do problema por lo abandono, por la carga familiar, sin preocuparse da carga sobre a família. Ou todo lo que es o homeless, os sin lugar, la gente que vive na área metropolitana de Paris, que vive nas calles de Nueva York o que vive dormiendo em São Paulo, en la calle. Eso está otra. É una delegación. Porque é una replicação do manicômio difundido. És un manicômio diluído. A metropolitana de Paris es un manicômio. Tem a misma regla: violento, no tem regla, abandono, tristeza. O hospital psiquiátrico horizontal. E finalmente el truco, o truque, a astúcia que fué la... Que passó en vários países. También na Itália passou esse caso. Muito passou em Espanha, que é a transinstitucionalização. Ou seja, eu cerro o hospital psiquiátrico que se chamava Hospital Psiquiátrico Santa Maria e abro uma vila para idosos com problemas mentales que se chama Santa Luíza. Também. Tudo igual. Um manicômio e outro. Mas um se chama mais manicômio e outro se chama Manicômio Santa Casa. Não também. Eso? Quatro fenômenos. O asilo, a desospitalização salvage, o abandono na calle e la transinstitucionalização são cien años de história de não resposta à discapacidad mental severa. Eu creio que uma coisa interessante - sobretudo para gente mais jovem - por que o Brasil e muitos outros han decidido de empezar um processo de desinstitucionalização? Manicômio é malo, é terrible. Es muy util. Tratar de pensar: por que a gente institucionalizou pacientes? Porque não é uma história de monstros, a história da psiquiatria. Se eram monstros ou se eram exclusivamente monstros, não haviam utilizado as melhores parques e vilas de las cidades de Itália. São manicômios que estão em lugares lindos, bonitos. E por quê? Porque havia uma intenção, padrão opressivo, repressivo, de ser violento? Mas havia uma intenção e um desenho ... Protección, proteção largo plazo para gente desprotegida. Assistência, dar comida, alimentação. Dar de dormir. De comer. Cuidado de largo plazo, cuidado con gran question: cuidado, 
que clase de cuidado? E alívio de la família. Porque é interessante analisar esos quatro elementos que justificam la institucionalização. Porque quando nosotros queremos cerrar um manicômio, queremos seguir protegendo a largo plazo sim. Queremos garantizar assistência en largo plazo sim. Queremos oferecer cuidados de largo plazo sim. Queremos aliviar a família sim. Pero sin muros. Sin institución. O sea, tenemos que guardar las razones profundas da la institucionalização e programar una psiquiatria que garantize esses cuatro elementos sin necesidad de una institución. Por eso se empeza o processo de desinstitucionalizar. Porque os usuários tenian cúmulos de sintomas de déficit, com maior discapacidad de vida no manicômio, mais aislamento social, que aumentava a desvantagem social. La baja calidad de los cuidados, las violaciones de los direitos humanos, la baja efectividad. O sea, um manicômio alto costo e muy baixa efectividad reabilitativa. Não reabilita para nada. E una tremenda insatisfação do usuário. O usuário não estava contento. Então estas, que ustedes conocen muy bién, que son las razones para que justifiqem a desinstitucionalização tem que no olvidarse qual foi la razón para institucionalizar a gente. Porque se usted cria un servicio na comunidade que no es de largo plazo e es de corto plazo, que está funcionando três horas por dia, que no está garantizando o alívio da família,que no está garantizando a proteção da vulnerabilidade e assistência ao paciente, usted está sendo um serviço comunitário de péssima calidad. Esta es la importancia. O sea, a desinstitucionalização no es solamente reduzir camas. No es solamente cerrar hospitales.

No es solamente aumentar altas de hospitales. Es un processo de empowerment de las personas con discapacidad mental. É a construção, de sua inclusão social, de sua cidadania. Não é um processo de engenharia institucional. Cerro, abro. Abro, cerro. Cerro, abro. Eso es parte. Pero no es. Es una cosa más... Más complicada. A terceira conectividade é la relação, conexão entre a reabilitação e reorientação do sistema de saúde mental. A reabilitação psicossocial não é uma técnica: aprender o paciente a cantar, a desenhar, fazer escultura. Não. Isso não é reabilitação. Essa não é a reabilitação.

A reabilitação, o processo de construção da cidadania é uma reconstrução do poder contratual do usuário, que tem implicação em uma modificacion radical do sistema de saúde mental. Se a reabilitação es um ateliê, um laboratório de pintura, eso não vai modificar o sistema de saúde mental do país, ou do estado ou da cidade. E eu sempre digo uma coisa - eu pido desculpa para os que... la escuchada - pero no puedo renunciar a decir que eu nunca vi. Porque además da desgracia que uma pessoa tem, que é de ser esquizofrênico, tem que ser também: artista, cantante, poeta, pintor. Por quê? Por quê? Tenemos que celebrar la santidad, la sacralidad da vida cotidiana. Vocês são todos pintores, 
cantores, escultores? Não. Quando vai na casa essa noite com a sua companheira, com o seu companheiro: quero expressar-me. Se senta, mira a televisão, toma una caipirinha, fala com um niño. Por que o paciente não pode terner eso? Normal. Não. Tem que ser... Tener una coral... É.

Entonces, a forte conectividade entre a reabilitação e câmbio do sistema de saúde mental. Porque a discapacidad mental es una condição crônica que requer cuidados de largo plazo. E en los cuidados de largo plazo está la diferencia entre institucionalizar e desinstitucionalizar. Donde ocurre? Ocurre en el contexto comunitário. Entonces, la desinstitucionalização es desospitalização sim. Pero es garantir cuidado de largo plazo dentro de um local comunitário, dentro da comunidade mesmo. E eso no ocurre. No ocurre principalmente porque la asignación de recursos no corresponde a la necessidade. La asignación es insuficiente, poca plata. E la asignación es ineficiente. La carga. La carga de la enfermedad mental comparada com la carga de todas las otras enfermedades existentes no mundo: câncer, cardiovasculares, diabetes, malária. La contribuição de la enfermedad mental es 13,14 , hasta $15 \%$ de toda la carga de discapacidades. Pero, el promedio, la asignación de recursos à saúde mental, en el promedio mundial es 3\% do orçamento de saúde. O sea, para tratar o $15 \%$ te doy 3\% do presupuesto de saúde.

Claro, com diferença importante. Esses são quatro situaciones. Esta é a classificação do Banco Mundial. Tem no link a la esquerda (slide), son los países de muy baixo ingreso: Haiti, Honduras. São país low midle; low midle quer dizer país como pode ser Jordânia. Pode ser países asiáticos como Sri Lanka. Hacia la direita (slide) hay os midle line, que é onde cabe o Brasil, a Índia, a China, que estão na terceira à esquerda, hacia la direita. E à direita extrema (slide) estão países muy ricos: Suécia, Noruega, Austrália, Canadá. E vocês veem toda la coluna amarelo mais... Amarelo mais rojo? Dice? Vermelho. Vermelho. Vermelho mais amarelo es lo que en el sobre los dólares para la salud, en general. El amarelo é la parte de dólares para salud mental. Entonces veam que en os países muy pobres la parte de dólares de salud que van para saúde mental es 1.5\%; 2.7 nos países mais ricos. Nos países como o Brasil é três punto algo. E nos países muy ricos é 6.8. Com diferencia importante, Inglaterra, por exemplo, gasta, en el mundo o que mais gasta , 14\% do presupuesto de saúde, na Inglaterra, é para saúde mental. Então, uma inversão importante. Pero lo que es interessante es que no es que los pobres tienem menos. Los pobre tienem muito menos. Porque la cantidad de dólares en la primeira coluna (slide), son pocos dólares. Entonces, el 1.5\% de poco. Mientras que en la coluna de direita es $6.8 \%$, é $6.8 \%$ do muito dólar. Entonces é o 6.8 de muito. E muito mais que o 1.5 do muy poco. 
Entonces la información que tuvimos desta transparência es que no solamente hay poco dinero para la salud mental. Mais o país pobre, mais pobre es a inversão em saúde mental. Ineficiência e no solamente. En nosso também hay insuficiência. Hay poco dinheiro. É como decia um amigo mio, economista, em uma conferência en Oxford, que causou muito escândalo. Ele é um economista e dijo: os psiquiatras no solamente son pobres. Reciben poco dinero. Son também cretinos. Porque o poco que reciben lo gastan muy mal. $62 \%$ do gasto de saúde mental no mundo se vá para casas psiquiátricas e manicômios. Solamente $20 \%$ se vá para hospital general, para camas psiquiátricas en hospital general e solamente una pequena parte se vá para estruturas residenciais comunitárias, casas de medio camino. A proposição da OMS e da OPAS é de invertir a pirâmide. A OMS recomenda que os $62 \%$ do presupuesto de saúde mental no sea para manicômios e sea para atencionar a comunidade ou residências protegidas. Mientras que solamente el 15\%, $12 \%$ se vá para manicômios.

Exatamente lo que Brasil hizo. E eu digo: segan sendo orgulhosos. Sean orgulhosos. Brasil es el único país no mundo que ha tenido a inversão do gasto. Há um momento del año 2000, aqui están los grandes chefes da saúde mental do país. Todos aqui sentados na primeira linha. El año, que no me acuerdo, 2005 me diz o Pedro Gabriel. 2005 o gasto da saúde mental no Brasil para manicômio está menor que o gasto de saúde mental do Brasil para atenção comunitária. Único país en el mundo que hubo esta inversão. Ustedes tem que defender esta inversão. E temo que vá tener una luta muy dura para que essa unicidade do Brasil. Que o Brasil é um modelo de referência para a OMS. Porque a OMS não pode tener Trieste como modelo. Trieste é uma cidade de meio milhão de habitantes. O Brasil es um continente. À China lhe interessa saber que passó em Brasil. $\mathrm{Na}$ Índia, está interessada que um país grande como o Brasil tuvo a capacidade de hacer una reforma. Se vocês perdem essa unicidade, de ser o país modelo para a OMS, desastre. Enonces hay que hacer una luta muito dura para defender essa unicidade, que para mim foi um privilégio. Eu venia a Brasil e voltava a Ginebra, à OMS e mira: esta é a referência. O sea, é una coisa importante.

En realidad, donde está el recurso? Donde está el dinero da saúde? Está en los hospitales psiquiátricos. Está en unidades especializadas que não têm área geográfica de captação definida. Eso es típico de muitos países de América Latina. Que hay un hospital de referência super sofisticado na capital, onde está um professor catedrático de psiquiatria. Que não tem nenhuma área de captação. Toda gente, de todo país quiere ir a esse hospital. Pois está o grande gênio. O gênio do eletrochoque. É. Ou la plata está em instituiciones privadas com o sin ajuda de governo, de la autoridad. Entonces hay 
errores sistêmicos, que son errores sistêmicos en el sentido epidemiológico, que recurre no sistema. Primeiro: hay demasiados hospitales psiquiátricos. Esse é um diagnóstico da OMS, no do senhor Saraceno. Hay demasiadas camas en los hospitales psiquiátricos. Que son dos problemas diferentes. Hay demasiados hospitales y hay demasiadas camas en los hospitales psiquiátricos. Hay un rechazo sistemático de las camas psiquiátricas en los hospitales generales. O sea, en algunos países ainda é uma solução importante também. Hay la falta total de soluciones alternativas para usuários de larga instância. Hay insuficientes centros de saúde mental na comunidade. E hay insuficientes conocimiento, formação e integração de saúde mental dentro da atención básica, dentro da atención primária. Atención primária sigue sendo muy poco preparada em trabalhar a saúde mental. E a saúde mental está desintegrada dos centrosbásicos.

Eu recordo o (.......) do David Capistrano, quando trabalhava com a medicina família. Então, integrar saúde mental dentro deste tipo de família. É uma coisa genial. Tem que estar muito difundido no país. Eso é um modelo de referência de saúde pública. Termino a minha conferência - tenho por 10 minutos - com um exemplo interessante: em 2015 eu fui invitado como consultor, como assessor para apoiar uma conferência de ministros. Vinte e quatro ministros de una parte del mundo que ustedes van ser surpreendidos, porque teníamos asi una ideia desta parte del mundo solamente ocurren coisas terrível. Pero no solamente cosas terribles. Eram os Países Árabes, 24 ministros. Estava Iraque, estava Síria, estava Jordânia, estava Palestina, estava Egito; 24 países. Na região da OMS incluía também o Paquistão, Países Árabes, digamos. Esos ministros convocaram durante - eu não estava - convocaram uma semana de intenso trabalho de um grupo, do grupo internacional, (...) para gerar recomendações(...). Esta recomendação que vou mostrar são recomendações de ministros. E não recomendações de espertos. Ou seja, os ministros assumiram e a linguagem que utilizam é impressionante, é uma linguagem inabitual. Vamos ver... O ministro disse "devido a que grandes instituições psiquiátricas tendem a oferecer serviços de baixa qualidade". Isso é uma afirmação importante. "Devido a atenção especializada com serviços na comunidade é mais efetiva se comparada a atenção prestada instituições centralizadas". Se reconhece que o modelo de atenção comunitária é mais [custo efetivo] devido a que existem intervenções custo-efetivas, que podem ser prestadas por não especialistas, estamos falando de países em que existe um Psiquiatra por quatrocentos mil habitantes. Ou seja, não há psiquiatras. Então há problema do ... ou seja, utilizar pessoal que não seja pessoal especializado para fazer psiquiatria. Então, essas são as três afirmações sobre as quais esses 24 ministros embasam sua política comum. Esse [...], dizem os ministros. 
Uma: integração mental em Sistemas de prestação de saúde.

Dois: [desarrolhar] a tensão na comunidade buscando alianças e sinergia de recursos, nesse caso uma linguagem nossa do movimento.

Três: estabelecer camas em hospitais Gerais como parte da saúde hospitalar. Reduzir e reformar hospitais psiquiátricos, melhorar a qualidade, racionalizar a utilização de recursos humanos e financeiros, sacar dinheiro.

Eu comecei a minha carreira em mil novecentos e noventa e cinco e o meu problema era convencer a sua excelência o senhor Ministro que havia manicômio. Ora, hoje em dois mil e quinze o problema não é convencer o ministro a cerrar manicômio, o ministro já sabe, o ministro já quer cerrar manicômio. É “como fazer". Ele quer a tecnologia para fazer. Não há que convencer que é melhor fazê-lo, há que convencê-lo que se pode fazê-lo. Como se pergunta aos ministros?

Primeiro: desarrolhar recursos humanos capacitados em Saúde Mental. Há um desafio, inovação de recrutar e capacitar recursos humanos. Mensagem importante: Paramos com cursos de capacitação que não tem nenhuma efetividade. Quando a gente não sabe (...) um curso e quando a gente está deprimida vai ao curso. Quando o professor não tem (...) reformado, é o professor do curso. O impacto é zero. Eu tenho experiência de curso do uso racional dos medicamentos. Se você quer ter o uso racional dos medicamentos não é o curso, é com supervisão, é com apoio de pessoas. É uma coisa muito mais sofisticada, é a supervisão e apoio, agente de supervisão primária. Não são ninhos que necessitam cursos, são colegas que necessitam apoio. É muito importante.

Segundo: empoderar ministros, empoderar usuários e família, nas ações de saúde mental. Desafio, estigma, discriminação entre profissional de saúde mental e profissional de saúde e a população em geral. Terceiro: o pressuposto tradicional e, claro, os ministros falam de pressuposto tradicional porque nossos economistas injetaram esta ideia. Para superar o manicômio ao momento em que eu gasto é [doble], você está financiando um sistema novo. Então é a fala de um pressuposto tradicional [que há um momento] e tem um problema delicado politicamente porque necessita o gestor e o político uma visão que saia do período eleitoral. (...) Nós temos calculado com economistas que os países que utilizaram mais tempo, foram 17 anos para passar de um sistema, passar do manicômio ao sistema de serviço de saúde mental comunitária então o gasto transacional durou pelo menos 10 anos. Há países em que foi mais rápido, é interessante ver, foi muito rápido a transição na comunidade, durante um tempo estava pagando o manicômio, estava pagando o centro de saúde mental da comunidade. Durou dois, três, quatro, cinco anos 
e depois o pressuposto estava somente em Saúde Mental comunitária. A que se fazer cálculos que o ministro entende. (...)

Quinto: superar a existência do hospital geral frente a [cama] psiquiátrica. há que ter uma negociação, para que o hospital geral (...) Oferecemos coisas importantes, o mundo da saúde geral em hospital geral.

Sexto: a questão de estrutura residencial de trabalho protegido e de apoio da família. É um desafio ... educação, alianças na comunidade, não se pode fazer a reabilitação comunitária sem alianças com outros setores da comunidade. A psiquiatria sozinha não vai encontrar todas as soluções. E finalmente o número sete: reformar, reduzir os hospitais psiquiátricos, melhorar a qualidade e o respeito pelos direitos humanos, cumprir com a convenção, os ministros de países árabes cumprir com a convenção, e desafio e resistência por parte dos profissionais, psiquiatras fundamentalmente, dos políticos, da organização familiar.

Eu tenho um exemplo da Argentina, o exemplo da Índia, o exemplo do Egito. Nos últimos cinco anos esses três países têm proposto lei de reformas de saúde mental avançadas, progressistas. E nesses, a sabotagem sistemática foi feita pelas associações psiquiátricas nesses três países. Na Argentina a lei de reforma da saúde mental foi aprovada pelo governo e a oposição. Eu fui ao parlamento falar em nome da OMS.

Essa lei é boa ( .... ) com esses juristas, todos. O único, porém, ... que não, que a lei era mala, que a lei autorizava psicólogos a ter mais importância, uma coisa delirante, e não psiquiatras solos. E foram derrotados ... Na Índia a lei ... está de acordo com a lei, mas queremos que haja um artigo que diz que o eletrochoque sem anestesia está autorizado. Porque, se não há anestésico, como fazer? Terceiro, Egito, com Mubarak, ditador presidente, um diretor de saúde mental no Egito que (...) as mulheres ou homens com hospitalização voluntária, compulsória, compulsiva...compulsória necessitam do certificado médico. A mulher simplesmente se fica, se o marido, o padre e o irmão diga: "está louca".

Segundo avaliação da qualidade dos direitos humanos no manicômio feita por psiquiatras do mesmo manicômio. Ou seja, eu me auto avalio. Digo: "não, aqui não há violação. Tá tudo bom”. Esses dois elementos, esse psiquiatra [no Egito] O doutor Nasser Losa foi à OMS pedir ajuda para mudar esses artigos [que são uma vergonha]. Apoiamos, ajudamos, e os artigos foram eliminados. As mulheres têm o mesmo direito que os homens de ter um certificado médico e para visitar manicômios e avaliar violação de direitos humanos há uma comissão externa que não tem conflito de interesses na avaliação. 
O Mubarak, na revolução do Egito, a Associação de psiquiatras do Egito disse: "Esta lei foi aprovada pelo ditador Mubarak.

Nós que somos democráticos rechaçamos essa lei aprovada pelo ditador e queremos reintegrar os dois artigos.” Foram reintegrados. E o que quero dizer? ... Eu visitei noventa países durante meus vinte e cinco anos como diretor de saúde mental da OMS, o obstáculo maior a reforma não são os ministros, não são os políticos, são os psiquiatras. Isso ..., e essa interessantíssima (...) de decisões tomadas por ministros me fazem concluir a minha conferência dizendo que os ministros são mais progressistas do que os psiquiatras.

Obrigado. 